\title{
The Influence of Refrigeration Method and Maturation Time in Broiler Meat Quality
}

\author{
Marius M. CIOBANU*, Roxana LAZĂR, Emanuiel C. DIACONU, Nicoleta GĂINĂ (DIACONU), \\ Paul C. BOIŞTEANU \\ Department of Fundamental Sciences in Animal Husbandry, University of Agricultural Sciences and \\ Veterinary Medicine Iaşi, 3 Mihail Sadoveanu Alley, 700490Iaşi, Romania; \\ *Corresponding author, email: mar.ciobanu@yahoo.com
}

Bulletin UASVM Animal Science and Biotechnologies 71(2) / 2014,

Print ISSN 1843-5262; Electronic ISSN 1843-536X

DOI:10.15835/buasvmcn-asb:10323

\begin{abstract}
Consumer acceptability of broiler meat depends on its tenderness and appearance, main cause of incidence hardness broiler meat cutting and boning the carcass before the completion of rigor mortis. Thus, to prevent apparition of rough meat literature describes a number of studies that focused on finding the optimum aging time. Prior to cutting and boning, to obtain juicy meat is needed to apply an early maturation period ranging between 4-6 h.

Meat color was expressed by tristim spectral coordinates $L^{*}, a^{*}, b^{*}$ colour space in $\operatorname{CIEL}^{*} a^{*} b^{*}$ (AMSA). To determine the force to Warner Bratzler was used texture-meter single bladed TA Instruments Lioyd plus $1 \mathrm{KN}$.

Descriptive analysis of meat quality parameters showed lower values for carcass chilling in drafts submitted for $\mathrm{pH}, \mathrm{L}^{*}, \mathrm{a}^{*}, \mathrm{~b}^{*}$ and WBSF significant differences $(\mathrm{P} \leq 0.05)$ were recorded for $\mathrm{pH}$, brightness and cooking losses. The curing time significantly influenced $(\mathrm{P} \leq 0.05)$ analyzed parameters. Acidity of meat, coordinate complementary colors red-green $\left(\mathrm{a}^{*}\right)$ and yellow-blue $\left(\mathrm{b}^{*}\right)$ and meat tenderness was assessed by a inverse relationship with increasing aging time.

The results described a negative correlation of losses by cooking refrigeration and maturation of acidity, coordinate complementary colors yellow-blue and Warner Bratzler shear force. The main negative effects of meat maturation were open colored pectoral muscle and increase losses by boiling.
\end{abstract}

Keywords: chicken, maturation, refrigeration.

\section{INTRODUCTION}

Consumer acceptability of broiler meat depends on its tenderness and appearance, main cause of incidence hardness broiler meat cutting and boning the carcass before the completion of rigor mortis (Fletcher, 2002).

Thus, to prevent apparition of rough meat literature describes a number of studies that focused on finding the optimum aging time. Prior to cutting and boning, to obtain juicy meat is needed to apply an early maturation period ranging between 4-6 h (Young, 1997; Northcutt et al., 2001; Liu et al., 2004). Maturation of carcasses is expensive because of the space required for storage and energy costs. Therefore, many processors prefer application immediately after chilling, the cutting and boning meat process that takes place in $0.5-0.83 \mathrm{~h}$ for cooling carcasses by immersing them in water (Veerkamp, 1990) and 1.5-2.5 $\mathrm{h}$ for cooling systems in air stream (James et al., 2006). To obtain an optimum maturity processors, stored carcasses at refrigeration temperature $\left(0-4^{\circ} \mathrm{C}\right)$ for another $2.5-4.5 \mathrm{~h}$ prior to the cutting and boning (Sams, 2002).

Previous studies have shown that high temperatures and slow cooling rates may accelerate post-mortem glycolysis and consequently the final texture of the meat, which means that its functional properties (Papinaho and Fletcher, 1996; McKee and Sams, 1998; Skarovsky and Sams, 1999; Alvarado and Sams, 2002).

However there is little information in the literature on comparing functionality broiler carcasses cut fillets, boneless prematurely and cooled 
either by immersion or air. From this perspective, the objective of the current study was to evaluate the effect of ripening time and cooling method on $\mathrm{pH}$, cooking losses, resulting meat color and tenderness.

\section{MATERIALS AND METHODS}

Prior to refrigeration, 150 carcasses of chickens (Ross 308) were removed from the slaughter line. $50 \%$ of the carcasses were subjected withdrawn dry air chilling method (RAU) and $50 \%$ were chilled by immersion in water (RIA). After application of the two types of refrigeration and 3 experimental groups formed based on the aging time $(0,2$ and 24 hours), at the end of maturation was done boning pectoral muscle that was subjected to analysis.

Determination of meat $\mathrm{pH}$ was performed at 0,2 and 24 hours post-slaughtering, the principle of analysis described by ISO 2917:2007, with digital $\mathrm{pH}$ meter with automatic reading of acidity and temperature HANNA HI 8424 subsequent corrections were made a function of temperature.

The color of the meat samples was done with a thickness of $15-50 \mathrm{~mm}$, which were sections perpendicular to the longitudinal axis of the muscle fiber. Meat color was expressed by tristim spectral coordinates $\mathrm{L}^{*}, \mathrm{a}^{*}, \mathrm{~b}^{*}$ color space in $\mathrm{CIEL}^{*}$ $a^{*} b^{*}$ (AMSA), measured by specular component included (SCI), the whole principle of operation of the spectrophotometer applying the specifications given in "CIE colorimeter Second Edition, Publication 15.2 (1986)".

As a method, the measurement itself was done in three different areas of each sample of meat Minolta CM-2600d portable spectrophotometer. Calibration was performed before each series of chromameter measurement using a calibration device Minolta CM-A32. The values obtained were converted and processed using software Spectra Magic v.3.30.

To determine the force to Warner Bratzler was used texture-meter single bladed TA Instruments Lioyd plus $1 \mathrm{KN}$, equipped with specific blade $\left(\Varangle=60^{\circ}\right)$ it is speed of $100 \mathrm{~mm} / \mathrm{min}$ under conditions of cutting force of $1,000 \mathrm{~N}$. Roll meat samples were sectioned on perpendicular direction of the muscle fibers, the maximum force required sectioning the sample being watched indicator for describing meat tenderness.

Software NEXYGEN Ondio, Ta Plus Series Integrated texture-meter allowed direct calculation of the values of shear forces on the cutting-strain curve, which is expressed in the form of peaks corresponding to the maximum recorded (Honikel, 1998), ensuring operation of the system texture-meter accordance with the requirements of BS EN ISO 7500:1999 set.

The data were processed by one-way analysis of variance in order to determine the effect of refrigeration type and storage time on each variable. Duncan's test was carried out to determine differences between groups. The level of statistical significance was $P \leq 0.05$. Pearson correlation was made to determine the interactions between variables and the influence of treatment on variables, with level of statistical of significance level of $P \leq 0.05$ and $P \leq 0.01$. Statistical analyses were performed using IBM SPSS software, v19

Tab. 1. Descriptive parameters of broiler meat quality (Mean \pm Standard Error of Mean)

\begin{tabular}{ccccccc}
\hline & \multicolumn{2}{c}{ Refrigeration type } & & \multicolumn{3}{c}{ Maturation time } \\
\cline { 2 - 3 } \cline { 5 - 7 } & RDA & RIW & & $0 \mathrm{~h}$ & $2 \mathrm{~h}$ & $24 \mathrm{~h}$ \\
\hline $\mathrm{pH}$ & $5.98 \pm 0.09$ & $6.28 \pm 0.09^{\mathrm{a}}$ & & $6.47 \pm 0.05^{\mathrm{c}}$ & $6.36 \pm 0.09^{\mathrm{c}}$ & $5.55 \pm 0.03$ \\
$\mathrm{~L}^{*}$ & $53.17 \pm 0.80$ & $56.58 \pm 0.77^{\mathrm{a}}$ & & $52.09 \pm 0.86$ & $54.55 \pm 0.65$ & $57.99 \pm 1.09^{\mathrm{ab}}$ \\
$\mathrm{a}^{*}$ & $1.68 \pm 0.20$ & $1.71 \pm 0.20$ & & $2.51 \pm 0.25^{\mathrm{bc}}$ & $1.79 \pm 0.14^{\mathrm{c}}$ & $0.77 \pm 0.14$ \\
$\mathrm{~b}^{*}$ & $2.20 \pm 0.23$ & $2.30 \pm 0.24$ & & $3.37 \pm 0.26^{\mathrm{bc}}$ & $2.12 \pm 0.16^{\mathrm{c}}$ & $1.25 \pm 0.23$ \\
Cooking loss & $24.92 \pm 0.78^{\mathrm{b}}$ & $21.29 \pm 0.70$ & & $21.90 \pm 0.99$ & $22.87 \pm 1.03$ & $24.56 \pm 0.91$ \\
WBSF & $12.90 \pm 0.79$ & $14.80 \pm 0.94$ & & $17.05 \pm 0.75^{\mathrm{c}}$ & $15.98 \pm 0.61^{\mathrm{c}}$ & $8.52 \pm 0.62$
\end{tabular}

Note: Results are based on two-sided tests assuming equal variances with significance level 0.05 . For each significant pair, the key of the smaller category appears under the category with larger mean. For each significant pair, the key of the smaller category appears under the category with larger mean. Tests are adjusted for all pair wise comparisons within a row of each innermost suitable using the Bonferroni correction.

RDA -dry air method; RIW -refrigerated by immersion in water; WBSF -Warner Bratzler Shear Force 


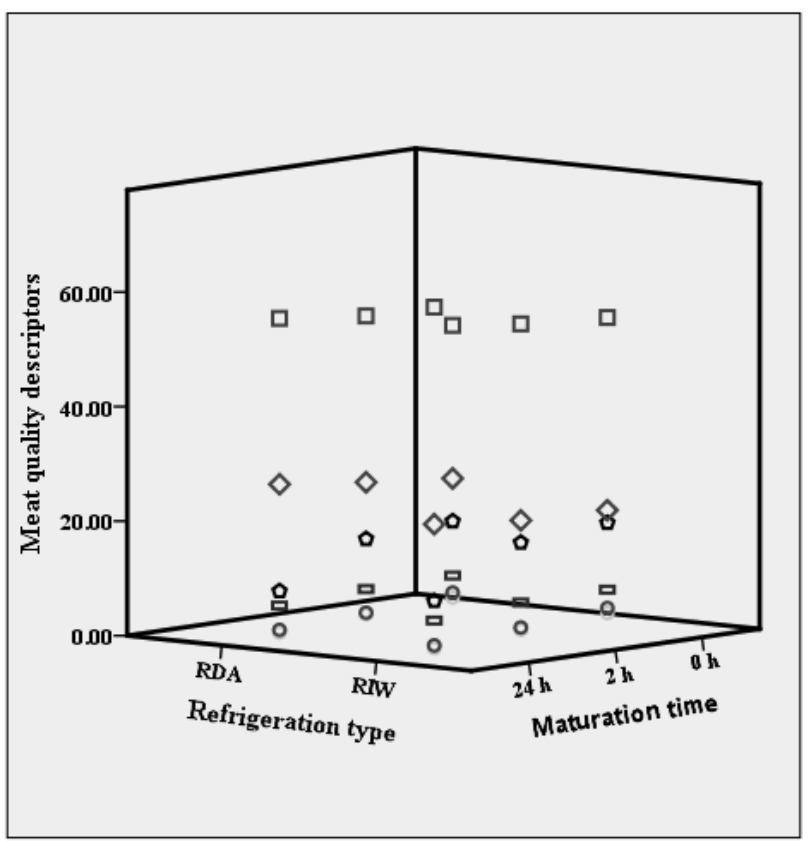

Fig. 1. Meat quality descriptors of broiler breast file in relation with refrigeration type and maturation time

(2010).

\section{RESULTS AND DISCUSSION}

Descriptive analysis of meat quality parameters (Tab. 1, Fig. 1) showed lower values for carcass chilling in drafts submitted for $\mathrm{pH}, \mathrm{L}^{*}, \mathrm{a}^{*}$, $\mathrm{b}^{*}$ and WBSF significant differences $(\mathrm{P} \leq 0.05)$ were recorded for $\mathrm{pH}$, brightness and cooking losses. The curing time significantly influenced $(\mathrm{P} \leq 0.05)$ analyzed parameters. Acidity of meat, coordinate complementary colors red-green $\left(a^{*}\right)$ and yellowblue $\left(b^{*}\right)$ and meat tenderness was assessed by an inverse relationship with increasing aging time.

By analyzing the interaction between qualitative determined parameters, the type of cooling and ripening period (Tab. 2) has shown significant effect $(\mathrm{P} \leq 0.05)$ moderately negative $(\mathrm{r}=-0.320) \mathrm{pH}$ on brightness and cooking losses ( $\mathrm{r}=-0.307)$, where $\mathrm{a}^{*}, \mathrm{~b}^{*}$ and tenderness (BSF) $\mathrm{pH}$ with a significant $(\mathrm{P} \leq 0.05)$ positive (Tab. 2$)$.

Statistical analysis flesh color not found any significant correlation $(\mathrm{P}>0.05)$ between it and boiling losses, but the latter parameter influencing negatively $(\mathrm{r}=-0.343)$ significantly $(\mathrm{P} \leq 0.05)$ tenderness of meat (Tab. 2).

Analyzing the influence of treatment was revealed moderate negative effect $(r=-0.413)$ significant losses chilling the cooked and ripening time on $\mathrm{pH}(\mathrm{r}=-0.764)$, coordinate complementary colors red-green ( $\mathrm{r}=-0.671)$ and Warner Bratzler shear force $(\mathrm{r}=-0.731)$ (increased tenderness) (Tab. 2).

Tab. 2. Coefficients of simple correlation (r) between meat qualitative studied parameters (a) and influence of experimental factors on meat quality descriptors (RDA, RIW, maturation time: 0, 2 and $24 \mathrm{~h})$

\begin{tabular}{|c|c|c|c|c|c|c|}
\hline \multirow{2}{*}{ Specification } & \multirow{2}{*}{$\mathrm{pH}$} & \multicolumn{3}{|c|}{ Color } & \multirow{2}{*}{ Cooking loss } & \multirow{2}{*}{ WBSF } \\
\hline & & $\mathrm{L}^{*}$ & $a^{*}$ & $\mathrm{~b}^{*}$ & & \\
\hline \multicolumn{7}{|c|}{ STUDIED PARAMETERS } \\
\hline $\mathrm{pH}$ & 1 & & & & & \\
\hline$L^{*}$ & $-0.320^{*}$ & 1 & & & & \\
\hline$a^{*}$ & $0.561^{* *}$ & $-0.380^{* *}$ & 1 & & & \\
\hline $\mathrm{b}^{*}$ & $0.568^{* *}$ & $-0.331^{* *}$ & $0.686^{* *}$ & 1 & & \\
\hline Cooking loss & $-0.307^{*}$ & 0.144 & 0.015 & -0.087 & 1 & \\
\hline WBSF & $0.749^{* *}$ & $-0.297^{*}$ & $0.492^{* *}$ & $0.422^{* *}$ & $-0.343^{* *}$ & 1 \\
\hline \multicolumn{7}{|c|}{ FACTORS } \\
\hline & \multicolumn{4}{|c|}{ Refrigeration } & Maturation & \\
\hline $\mathrm{pH}$ & \multicolumn{4}{|c|}{$0.296^{*}$} & $-0.764^{* *}$ & \\
\hline $\mathrm{L}^{*}$ & \multicolumn{4}{|c|}{$0.375^{* *}$} & $0.529 * *$ & \\
\hline$a^{*}$ & \multicolumn{4}{|c|}{0.014} & $0.658^{* *}$ & \\
\hline $\mathrm{b}^{*}$ & \multicolumn{4}{|c|}{0.039} & $-0.671^{* *}$ & \\
\hline Cooking loss & \multicolumn{4}{|c|}{$-0.413^{* *}$} & 0.247 & \\
\hline WBSF & \multicolumn{4}{|c|}{0.199} & $-0.731^{* *}$ & \\
\hline
\end{tabular}

Note: WBSF - Warner Bratzler Shear Force; RDA - dry air method; RIW - refrigerated by immersion in water;

*Correlation is significant at 0.05 level (2-tailed)

**Correlation is significant at 0.01 level (2-tailed) 


\section{CONCLUSION}

The results described a negative correlation of losses by cooking refrigeration and maturation of acidity, coordinate complementary colors yellowblue and Warner Bratzler shear force. The main negative effects of meat maturation were open colored pectoral muscle and increase losses by boiling. After $24 \mathrm{~h}$, Warner Bratzler shear force values for RIW and RDA meat were $<4.62 \mathrm{~kg}$ and corresponded by sensory categories from soft to very soft. Results showed that refrigeration by air chilling has an effect on acceleration of rigor mortis, so we recommend 24-36 h maturation.

\section{REFERENCES}

1. Alvarado CZ and Sams AR (2002). The role of carcass chilling rate in the development of pale, exudative turkey pectoralis. Poultry Science 81:1365-1370.

2. Fletcher DL (2002). Poultry meat quality. World's Poultry Science 58:131-146.

3. Honikel KO (1998). Reference methods for the assessment of physical characteristics of meat. Meat Science 49(4): 447-457.

4. James C, Vincent C, Andrade Lima TI and James SJ (2006) The primary chilling of poultry carcasses - a review. Int J Refrig. Vol. 29:847-862.

5. Liu Y, Lyon BG, Windham WR, Lyon CE and Savage EM (2004). Principal component analysis of physical, colour and sensory characteristics of chicken breasts deboned at two, four, six, and twenty-four hours post-mortem. Poultry Science 83:101-108.

6. McKee SR and Sams AR (1998). Rigor mortis development at elevated temperatures induces pale exudative turkey meat characteristics. Poultry Science 77:169-174.

7. Northcutt JK, Buhr RJ, Young LL, Lyon CE and Ware GO (2001). Influence of age and postchill carcass aging duration on chicken breast fillet quality. Poultry Science 80:808-812.

8. Papinaho PA and Fletcher DL (1996). The influence of temperature on broiler breast muscle shortening and extensibility. Poultry Science 75:797-802.

9. Sams A (2002). Post-mortem electrical stimulation of broilers. World's Poultry Science Journal 58:147-157.

10. Skarovsky CJ and Sams AR (1999). Tenderness, moisture loss and post-mortem metabolism of broiler pectoralis muscle from electrically stimulated and air chilled carcasses. Br. Poultry Science 40:622-625.

11. Veerkamp $\mathrm{CH}$ (1990). Chilling of poultry and poultry products 147-158 in Chilled Foods - The State of Art, TR Gormley, ed. Elsevier Appl. Sci.

12. Young LL (1997). Effect of post-chill deboning on tenderness of broiler breast fillets, J. Appl. Poult. Res 6:174-179.

13. *** Colorimetry, Second Edition, Publication CIE no. 15.2 (1986), cited in: International Commission on Illumination - Technical Report, online at:

14. https://law.resource.org/pub/us/cfr/ibr/003/cie.15. 2004.pdf

15. *** SR ISO 2917:2007. Carne și produse din carne. Măsurarea pH-ului. Metoda de referinţă. 